Bull. Chem. Soc. Ethiop. 2021, 35(3), 525-535.

(c) 2021 Chemical Society of Ethiopia and The Authors

ISSN 1011-3924

DOI: https://dx.doi.org/10.4314/bcse.v35i3.5

Printed in Ethiopia

Online ISSN 1726-801X

\title{
SPECTRAL CHARACTERIZATION AND BIOLOGICAL STUDIES OF SOME TERNARY COMPLEXES WITH MOLECULAR DOCKING INVESTIGATIONS AGAINST MERS AND SARS TYPE CORONAVIRUSES
}

\author{
V.P. Saikishore ${ }^{1}$, Susanta Kumar Biswal ${ }^{1 *}$ and Ranjan K. Mohapatra ${ }^{2 *}$ \\ ${ }^{1}$ Department of Chemistry, Centurion University of Technology and Management, Odisha, India \\ ${ }^{2}$ Department of Chemistry, Government College of Engineering, Keonjhar, Odisha, India
}

(Received September 14, 2020; Revised January 20, 2022; Accepted January 23, 2022)

\begin{abstract}
A series of ternary complexes with a Schiff base (HL1) derived from 2-hydrazinobenzimidazole and $o$-hydroxybenzophenone (primary ligand) have been prepared. Here, 1,10-phenanthroline acts as secondary ligand (L2). These metal complexes were investigated by UV-Vis, IR, ${ }^{1} \mathrm{H}$ NMR and thermal techniques. The spectral data confirmed tridentate nature of the SB ligand with NNO type coordination, whereas the secondary ligand L2 (1,10-phenanthroline) coordinated through its two nitrogen atoms (NN type). These compounds possess distorted octahedral geometry. Moreover, these compounds were screened against B. subtilis and E. coli to evaluate their antibacterial activity. In addition, molecular docking studies were performed against MERS-CoV and SARS-CoV2 main protease (Mpro). Moreover, DFT calculations and QSAR studies of the SB ligand were also performed.
\end{abstract}

KEY WORDS: Ternary complexes, Spectral, Antibacterial, DFT, QSAR, Molecular docking studies

\section{INTRODUCTION}

For the synthesis of various Schiff base (SB) compounds, benzimidazole acts as an important precursor. Benzimidazole, its derivatives and their metal complexes have displayed remarkable biological activities. The effectiveness of these compounds increases on coordination to metal ions. Now-a-days, the mixed ligand metal complexes (also called ternary compounds) have gained considerable attention as they offer a wide variety of donor atoms and different geometries to the central metal ions $[1,2]$. The structural diversity has triggered a wide range of applications of this class of compounds in chemical, biochemical and biological fields [3]. As reported earlier, such compounds displayed catalytic [4], antimicrobial [5, 6], antioxidant [7], DNA interaction [8] and cytotoxic $[9,10]$ activities. Moreover, the interaction of 2-(2'-hydroxyphenyl)benzimidazole and its analogues with bovine serum albumin was explored and on interaction both normal and tautomer emissions are found to be enhanced significantly [11]. Keeping in mind such versatile nature of these compounds, we have tried to report the synthesis of some ternary complexes having benzimidazole moiety.

The emerging pathogenic viral infection COVID-19 originating from Huanan Sea food wholesale market of China has affected almost the whole planet [12]. This outbreak has destroyed significantly the global economy and the stock market. This is the most critical health disaster we ever seen and has continued since last two years. The emergence of large number of variants of concerns (Alpha, Beta, Gamma, Delta and Omicron), along with other variants of SARS-CoV-2 are responsible for this never ending pandemic $[13,14]$. Moreover, no effective drugs or vaccines are yet developed and we are still searching new compounds capable of contrasting the virus by using several computational strategies $[15,16]$. So, in this work, we have performed the docking study of these newly synthesized ternary complexes against MERS-CoV and SARS-CoV-2 main protease.

\footnotetext{
*Corresponding author. E-mail: dr.skbiswal@cutm.ac.in ; ranjank_mohapatra@yahoo.com This work is licensed under the Creative Commons Attribution 4.0 International License
} 


\section{EXPERIMENTAL}

The metal salts and the chemicals were purchased from Sigma Aldrich and used as such. The UVVis spectra were recorded in DMSO on a Perkin-Elmer spectrophotometer. The FTIR spectra in $\mathrm{KBr}$ pallets were obtained from Varian FT-IR spectrophotometer, Australia. TGA was carried out by a Netzch-429 thermo analyzer. CHN contents were determined from a MLW-CHN micro analyzer whereas, the metal contents were examined gravimetrically [17]. The molar conductance and magnetic susceptibility measurements have been carried out with Toshniwal conductivity Bridge and Gouy method, respectively. In addition, the ${ }^{1} \mathrm{H}-\mathrm{NMR}$ spectra in DMSO- $\mathrm{d}_{6}$ medium were recorded on a JEOL GSX-400 model.

\section{Preparation of mixed ligand complexes}

The SB ligand (HL1) was obtained from the condensation of 2-hydrazinobenzimidazole and $o$ hydroxybenzophenone as reported earlier [18]. The hot ethanolic solution of SB ligand (0.01 mol, $20 \mathrm{~mL})$, metal(II) salt $(0.01 \mathrm{~mol}, 20 \mathrm{~mL})$ and 1,10-phenanthroline $(0.01 \mathrm{~mol}, 20 \mathrm{~mL})$ were mixed with stirring in 1:1:1 molar ratio and refluxed for 3-4 hours. The $\mathrm{pH}$ of the reaction mixture was adjusted to $7-8$ by adding little of solid $\mathrm{NaOH}$. The resulting mixture was cooled, filtered, washed and finally, dried in vacuo. The synthesized compounds are soluble in DMSO and DMF and all of them decompose above $250^{\circ} \mathrm{C}$. The schematic representation for the preparation of the ternary compounds is shown in Figure 1.

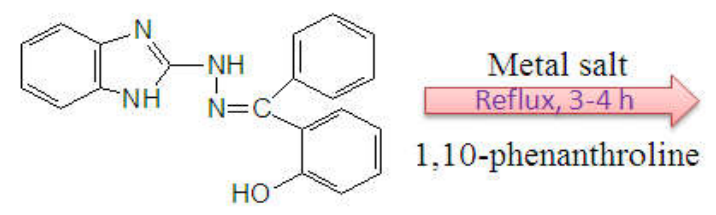

SB ligand

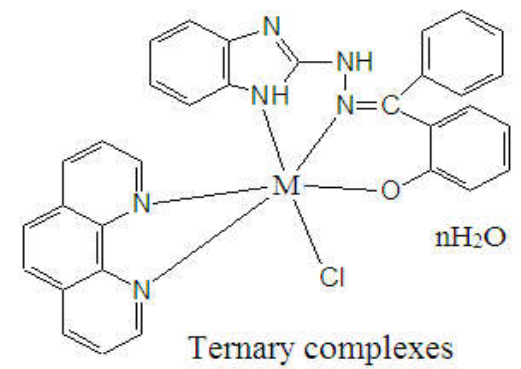

Figure 1. Synthesis of ternary complexes, [M= Co(II), Ni(II), $\mathrm{Cu}(\mathrm{II})$ and $\mathrm{Zn}(\mathrm{II})]$.

Complex 1: [CoL1L2Cl] $\mathrm{H}_{2} \mathrm{O}$. Yield 69\%; anal. calc. (\%): C, 61.98; H, 4.03; N, 13.56; M, 9.52. Found (\%): C, 61.82.02; H, 3.95; N, 13.50; M, 9.43.

Complex 2: [NiL1L2Cl] $\mathrm{H}_{2} \mathrm{O}$. Yield 70\%; anal. calc. (\%): C, 62.03; H, 4.04; N, 13.57; M, 9.45. Found (\%): C, 61.88; H, 3.98; N, 13.51; M, 9.39.

Complex 3: [CuL1L2Cl] $2 \mathrm{H}_{2} \mathrm{O}$. Yield 65\%; anal. calc. (\%): C, 59.81; H, 3.89; N, 13.08; M, 9.89. Found (\%): C, 59.73; H, 3.84; N, 13.02; M, 9.82.

Complex 4: [ZnL1L2Cl] $\mathrm{H}_{2} \mathrm{O}$. Yield 67\%; anal. calc. (\%): C, 61.39; H, 3.99; N, 13.43; M, 10.39 . Found (\%): C, 61.27; H, 3.95; N, 13.38; M, 10.32.

\section{RESULTS AND DISCUSSION}

IR spectra

The central metal ion is coordinated through the deprotonated $(\mathrm{OH})$ phenolic oxygen which was confirmed from the disappearance of band due to phenolic -OH stretching 
vibration. The band due to $v_{\mathrm{N}-\mathrm{H}}$ (exocyclic) remains practically unaltered in the present complexes indicating its non-involvement ( $\mathrm{N}$-atom) in coordination. Moreover, the non coordination of $-\mathrm{C}=\mathrm{N}$ ring nitrogen (benzimidazole) was also suggested. The coordination of benzimidazole N-H group $\left(\sim 3150 \mathrm{~cm}^{-1}\right)$ was confirmed as it shifted $(\sim 20$ $\left.\mathrm{cm}^{-1}\right)$ to lower frequency region. Moreover, the azomethine band $\left(v_{\mathrm{C}=\mathrm{N}}\right)$ was shifted in the ternary compounds implying the participation of azomethine nitrogen $(\mathrm{C}=\mathrm{N})$ atom in coordination [18]. Furthermore, the absorption at $\sim 3350 \mathrm{~cm}^{-1}$ is due to $v_{\mathrm{O}-\mathrm{H}}$ of lattice water molecules present in the ternary compounds. In addition, a band at $\sim 1100-1120 \mathrm{~cm}^{-1-1}$ for $v(\mathrm{C}=\mathrm{N})$ was also observed for these complexes which may be of 1,10-phenanthroline [19].

\section{Electronic spectra}

The UV-Vis spectrum of cobalt complex contains two bands at $\sim 10,560 \mathrm{~cm}^{-1}$ and $\sim 22,210$ $\mathrm{cm}^{-1}$ for ${ }^{4} \mathrm{~T}_{1 \mathrm{~g}}(\mathrm{~F}) \rightarrow{ }^{4} \mathrm{~T}_{2 \mathrm{~g}}(\mathrm{~F})\left(v_{1}\right)$ and ${ }^{4} \mathrm{~T}_{1 \mathrm{~g}}(\mathrm{~F}) \rightarrow{ }^{4} \mathrm{~T}_{1 \mathrm{~g}}(\mathrm{P})\left(v_{3}\right)$ transitions respectively with $\mu_{\mathrm{eff}}$ value of $4.76 \mathrm{BM}[20]$. The former band is assigned to ${ }^{4} \mathrm{~T}_{1 \mathrm{~g}}(\mathrm{~F}) \rightarrow{ }^{4} \mathrm{~T}_{2 \mathrm{~g}}(\mathrm{~F})\left(v_{1}\right)$ whereas the later band is for ${ }^{4} \mathrm{~T}_{1 \mathrm{~g}}(\mathrm{~F}) \rightarrow{ }^{4} \mathrm{~T}_{1 \mathrm{~g}}(\mathrm{P})\left(v_{3}\right)$ transitions [20]. The nickel complex showed bands at $\sim 8,720 \mathrm{~cm}^{-1}, \sim 10,575 \mathrm{~cm}^{-1}, \sim 15,160 \mathrm{~cm}^{-1}$ and $\sim 24,000 \mathrm{~cm}^{-1}$. The last two bands assigned to ${ }^{3} \mathrm{~A}_{2 \mathrm{~g}}(\mathrm{~F}) \rightarrow{ }^{3} \mathrm{~T}_{1 \mathrm{~g}}(\mathrm{~F})\left(v_{2}\right)$ and ${ }^{3} \mathrm{~A}_{2 \mathrm{~g}}(\mathrm{~F}) \rightarrow{ }^{3} \mathrm{~T}_{1 \mathrm{~g}}(\mathrm{P})\left(v_{3}\right)$ transitions respectively (under octahedral field) whereas, the former bands are due to ${ }^{3} \mathrm{~B}_{1 \mathrm{~g}} \rightarrow{ }^{3} \mathrm{E}_{\mathrm{g}}$ and ${ }^{3} \mathrm{~B}_{1 \mathrm{~g}} \rightarrow{ }^{3} \mathrm{~B}_{2 \mathrm{~g}}$, respectively. In addition, the observed $\mu_{\text {eff }}$ value of $2.91 \mathrm{BM}$ suggests octahedral $\mathrm{Ni}(\mathrm{II})$ species. The $\mathrm{Cu}$ (II) complex exhibited two bands at $\sim 14,470 \mathrm{~cm}^{-1}$ and $\sim 16,825 \mathrm{~cm}^{-1}$, which are due to ${ }^{2} \mathrm{~B}_{1 \mathrm{~g}} \rightarrow{ }^{2} \mathrm{~B}_{2 \mathrm{~g}}\left(v_{2}\right)$ and ${ }^{2} \mathrm{~B}_{1 \mathrm{~g}} \rightarrow{ }^{2} \mathrm{E}_{\mathrm{g}}\left(v_{3}\right)$ transitions. The electronic bands and $\mu_{\text {eff }}$ value $(1.83 \mathrm{BM})$ suggests a distorted octahedral geometry for $\mathrm{Cu}(\mathrm{II})$ complex.

\section{Thermal analysis}

The ternary compounds showed similar pattern of thermal decomposition and the TGA data are listed in Table 1. All the metal complexes lose water in the temperature range below $100{ }^{\circ} \mathrm{C}$ indicating them to be lattice water [21-23]. The anhydrous metal complexes showed two stages of thermal decompositions between $210-320^{\circ} \mathrm{C}$ and $360-610^{\circ} \mathrm{C}$. The degradation of available organic constituents continues till the formation of stable metal oxide as end product.

Table 1. The TGA data of the reported compounds.

\begin{tabular}{|c|c|c|c|c|c|c|}
\hline Compounds & \multirow{2}{*}{$\begin{array}{l}\text { Temp. range of } \\
\text { water loss }\left({ }^{\circ} \mathrm{C}\right)\end{array}$} & \multicolumn{2}{|c|}{$\%$ of water } & \multicolumn{2}{|c|}{ loss of residue } & $\begin{array}{c}\text { Composition of } \\
\text { the residue }\end{array}$ \\
\cline { 3 - 6 } & & Found & Calc. & Found & Calc. & \\
\hline$[\mathrm{CoL} 1 \mathrm{~L} 2 \mathrm{Cl}] \mathrm{H}_{2} \mathrm{O}$ & $50-100$ & 2.85 & 2.90 & 12.04 & 12.10 & $\mathrm{CoO}$ \\
\hline$[\mathrm{NiL} 1 \mathrm{~L} 2 \mathrm{Cl}] \mathrm{H}_{2} \mathrm{O}$ & $60-110$ & 2.83 & 2.90 & 11.98 & 12.03 & $\mathrm{NiO}$ \\
\hline$[\mathrm{CuL} 1 \mathrm{~L} 2 \mathrm{Cl}] 2 \mathrm{H}_{2} \mathrm{O}$ & $50-100$ & 5.52 & 5.60 & 12.32 & 12.38 & $\mathrm{CuO}$ \\
\hline$[\mathrm{ZnL} 1 \mathrm{~L} 2 \mathrm{Cl}] \mathrm{H}_{2} \mathrm{O}$ & $55-110$ & 2.79 & 2.87 & 12.88 & 12.95 & $\mathrm{ZnO}$ \\
\hline
\end{tabular}

${ }^{1}$ H NMR spectra

The ${ }^{1} \mathrm{H}$ NMR spectrum of $\mathrm{Zn}(\mathrm{II})$ complex was compared with the spectrum of the SB ligand. The ${ }^{1} \mathrm{H}$ NMR spectrum (Figure 2) showed a multiplet at $\delta$ 7.4-7.8 ppm may be for phenyl group protons of the $\mathrm{Zn}(\mathrm{II})$ complex. On comparison, the downfield shift of the signal $(\delta 6.9$ ppm) for ring $\mathrm{NH}$ indicates its participation in coordination [18]. However, the signal due to exocyclic NH proton observed at $\delta 9.1 \mathrm{ppm}$ indicates its noninvolvement in coordination. In addition, the signal due to phenolic -OH proton disappeared from the spectrum which confirmed the involvement of phenolic oxygen in co-ordination through deprotonation. 


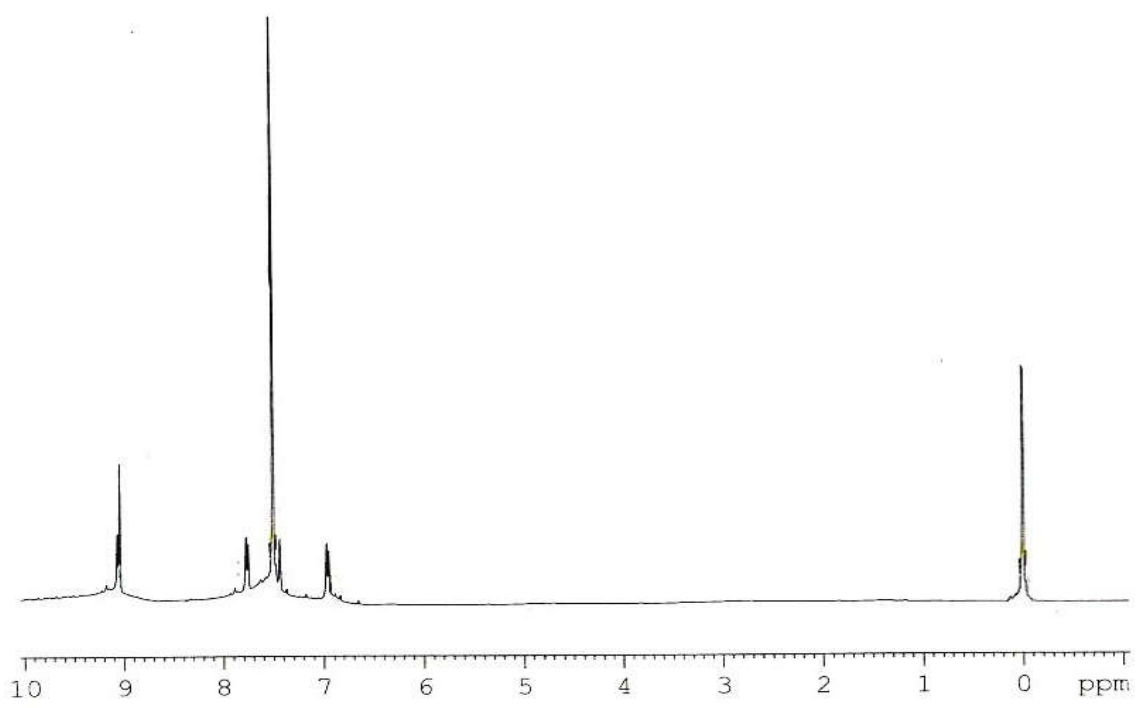

Figure 2. ${ }^{1} \mathrm{H}$ NMR spectrum of $\mathrm{Zn}(\mathrm{II})$ complex.

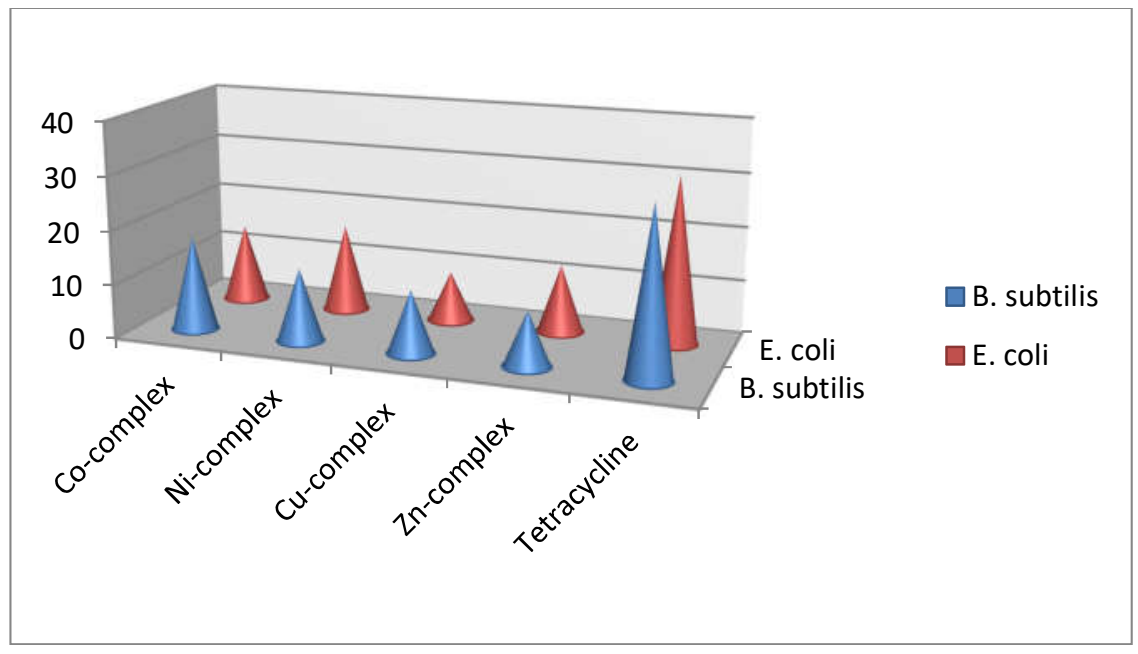

Figure 3. The ZI (mm) data of the ternary complexes (for a concentration of $100 \mu \mathrm{g} \mathrm{mL}^{-1}$ ).

\section{Antibacterial activity}

The antibacterial activity of these studied compounds was investigated by using agar well method $[24,25]$ against $B$. subtilis and E. coli. The test solution $\left(3 \times 10^{-3} \mathrm{M}\right)$ was prepared in DMSO. The test samples were leveled in sterile disc and incubated at $37^{\circ} \mathrm{C}$ for $24 \mathrm{~h}$. The results were determined from the diameter of inhibition zone (IZ) in $\mathrm{mm}$ and shown in Figure 3. As per the study, the investigated compounds displayed weak to moderate activity against both the strains. The $\mathrm{Co}(\mathrm{II})$ and $\mathrm{Ni}(\mathrm{II})$ complexes displayed greater activity than the free ligand reported 
earlier. This may be explained due to the presence of $\mathrm{C}=\mathrm{N}$ bonds and coordination [26]. In this study, DMSO acts as the negative control whereas; tetracycline is the used standard reference drug.

\section{Molecular docking study}

To examine the biological activity, the docking study was performed by using CLC Drug Discovery Software [27]. The interactions between the studied compounds and the protein/enzyme receptor were analysed. The used receptors were imported from the protein data bank (MERS-CoV (PDB ID: 4ZS6 [28]) and SARS-CoV-2 (PDB ID: 6W63 [29]) main protease. The protocols for the CLC Drug Discovery Workbench Software were followed as per our previous reports [6].

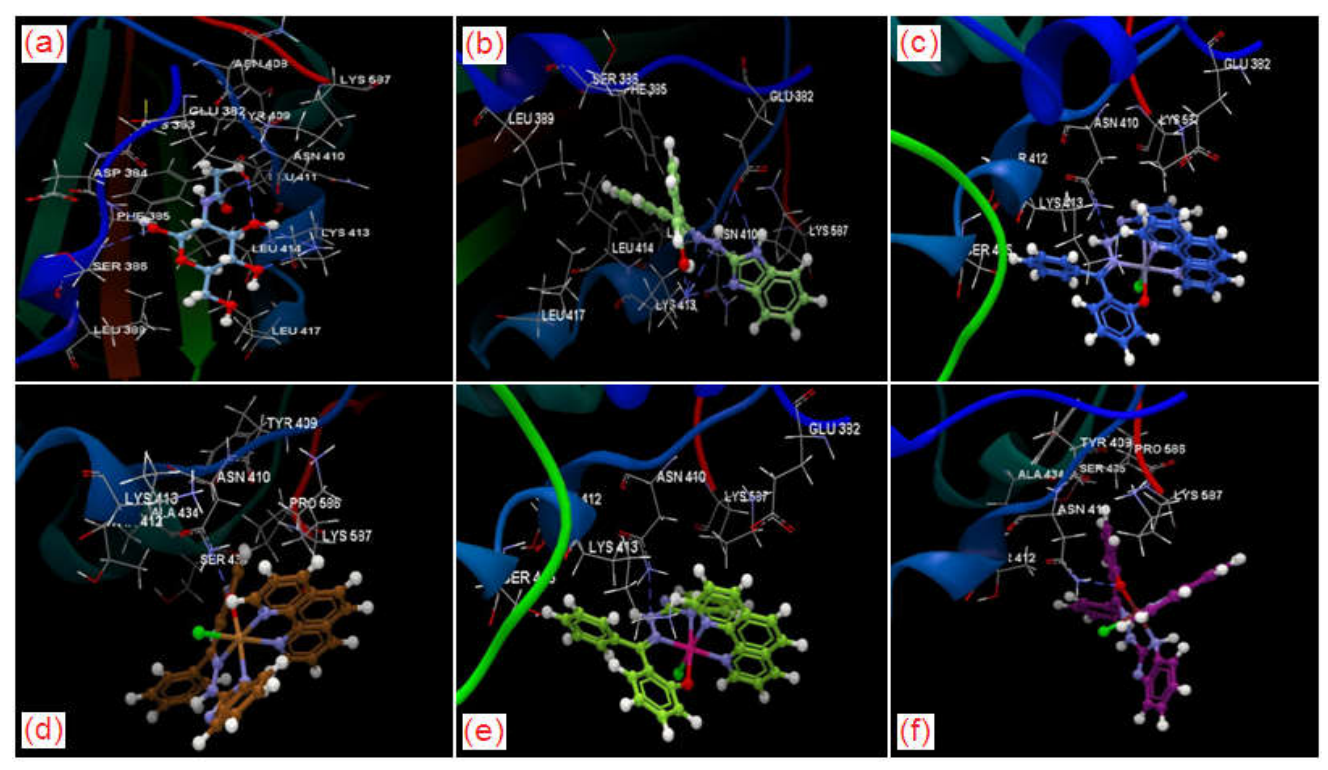

Figure 4. (a) Docking pose of the co-crystallized ligand, (b) SB Ligand, (c) Zn-complex, (d) Cucomplex, (e) Co-complex, and (f) Ni-complex, interacting with the amino acid residues of binding site of 4Z6S.

\section{Docking evaluation against MERS-CoV}

The investigated compounds (called ligands) have been docked on the crystal structure of MERS$\mathrm{CoV}$. The docking pose of the co-crystallized NAG (N-acetyl-D-glucosamine, reference ligand) interacting with amino acid residues of the active site are shown in Figure 4a, which showed the occurrence of 6 hydrogen bonds with GLU 382, LYS 413, PHE 385 and SER 386. The docking score of all these reported metal-complexes is higher as compared to the co-crystallized NAG (docking score: -21.63; RMSD: $0.04 \AA$ ) but smaller than the SB ligand (docking score: -33.14; RMSD: $0.06 \AA$ ). The SB ligand showed occurrence of 6 hydrogen bonds: two with GLU 382 $(3.225 \AA$ and $2.863 \AA$ ), and four with LYS 413 (2.952 $\AA, 2.899 \AA, 2.693 \AA$ and $2.880 \AA)$. The Zn-complex showed best docking score (-31.35; RMSD: 0.14) and displayed occurrence of one hydrogen bond with ASN 410 (2.921 $\AA$ ). Moreover, Cu-complex (2.636 $)$, Co-complex (2.886 
$\AA)$ and Ni-complex $(2.712 \AA$ ) realized one hydrogen bond with ASN 410 amino acid. The docking pose of the SB ligand and metal complexes, interacting with the amino acid residues is presented in Figure 4b-f.

\section{Docking evaluation against SARS-CoV-2 main protease}

The studied compounds have been docked again on the crystal structure of SARS-CoV-2 main protease. The docking pose of the co-crystallized X77 (reference ligand) interacting with amino acid residues and the hydrogen bond created with GLU 166 and GLY 143 are observed (Figure 5). The docking score of all these studied metal-complexes is higher than the co-crystallized $X 77$ (docking score: -56.57; RMSD: $1.53 \AA$ ), and the SB ligand (docking score: -61.60; RMSD: 0.98 $\AA)$. The SB ligand showed occurrence of two hydrogen bonds: one with GLU166 (3.054 $\AA$ ) and one with GLN 189 (2.903 $\AA$ ). The Cu-complex showed best docking score (-70.31; RMSD: 0.03$)$ and showed occurrence of one hydrogen bond with GLU 166 (3.268 $\AA$ ). Moreover, Zn-complex $(3.215 \AA)$, Co-complex $(3.268 \AA)$ and Ni-complex (3.264 $\AA$ ) realized one hydrogen bond with GLU166 amino acid. The docking pose of the co-crystallized X77, SB ligand and the metal complexes interacting with the amino acids residues are presented in Figure 5a-f.

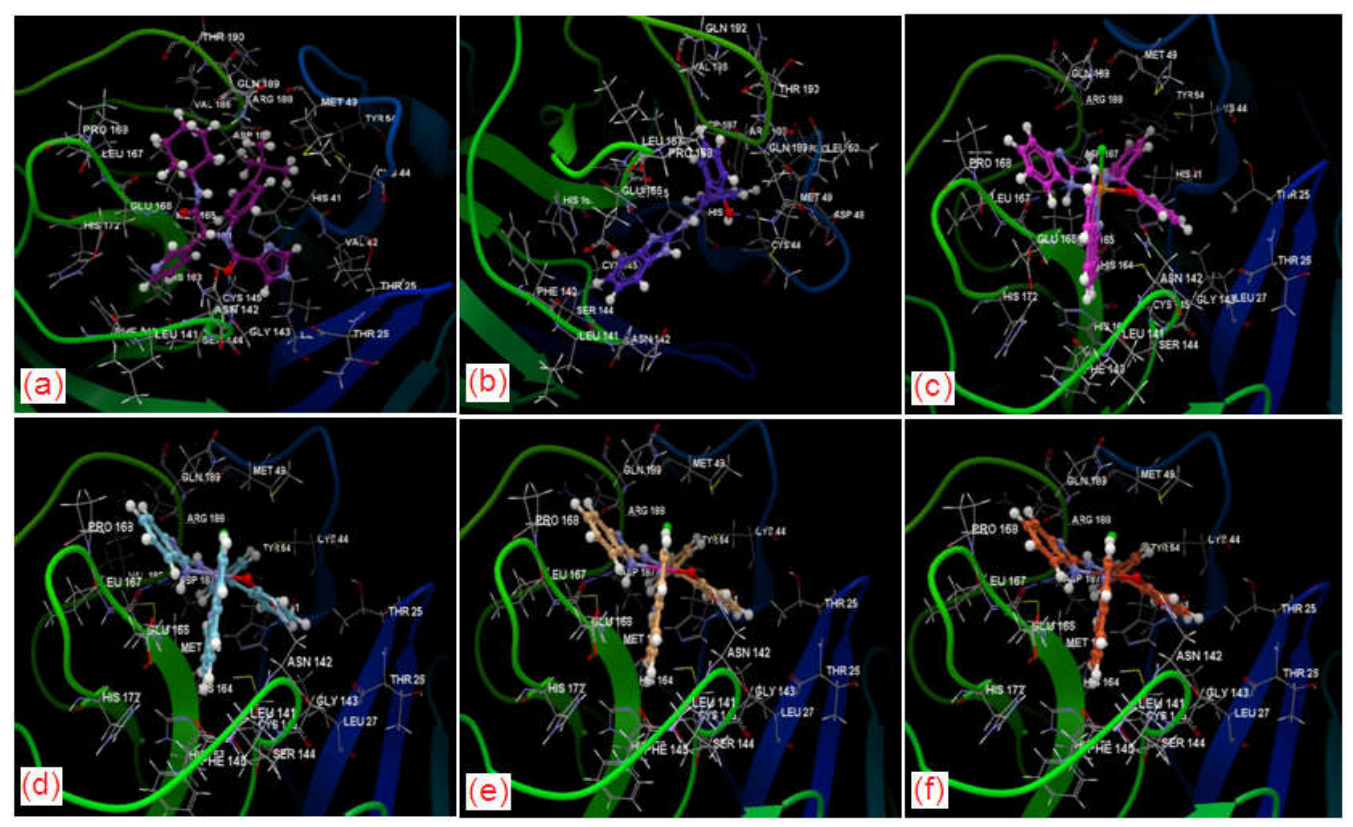

Figure 5. (a) Docking pose of the co-crystallized ligand, (b) SB Ligand, (c) Cu-complex, (d) Zncomplex, (e) Co-complex, and (f) Ni-complex, interacting with the amino acid residues of binding site of $6 \mathrm{~W} 63$.

After analyzing, it was also observed that only the SB ligand has the same orientation as the co-crystallized NAG, and all the metal complexes have a different orientation than the cocrystallized NAG. The docking score (PLANTS PLP score) is a function described in Korb and coworkers [30]. The Lipinski parameters [31] have been calculated and are tabulated (Table 2). The number of violations allows to evaluate drug likeness for the molecule and these metal complexes have two violations of all the parameters (Lipinski violation is 2). 
Table 2. The calculated properties of the investigated compounds.

\begin{tabular}{|c|c|c|c|c|c|c|c|}
\hline Compounds & 蒁 & 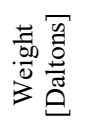 & $\begin{array}{l}\frac{0}{0} \\
\frac{0}{0} \\
\frac{0}{0} \\
0\end{array}$ & 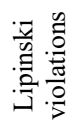 & 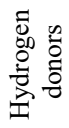 & 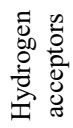 & $\log P$ \\
\hline $\begin{array}{c}\text { Co-crystallized* NAG A } \\
701\end{array}$ & 30 & 221.21 & 2 & 0 & 5 & 7 & -2.54 \\
\hline Co-crystallized $* *$ X77 & 66 & 458.58 & 7 & 0 & 1 & 7 & 4.59 \\
\hline SB Ligand & 41 & 328.37 & 4 & 0 & 3 & 5 & 4.96 \\
\hline Co-Complex & 64 & 601.95 & 1 & 2 & 2 & 7 & 8.91 \\
\hline Ni-Complex & 64 & 601.71 & 1 & 2 & 2 & 7 & 8.91 \\
\hline Zn-Complex & 64 & 608.43 & 1 & 2 & 2 & 7 & 8.91 \\
\hline $\mathrm{Cu}-\mathrm{Complex}$ & 64 & 606.56 & 1 & 2 & 2 & 7 & 8.91 \\
\hline
\end{tabular}

* PDB ID: 4ZS6; ** PDB ID: 6W63.

\section{Computational (DFT) study}

The Schiff base ligand was first optimized and the geometry was studied with the help of Gauss View 5.0.8. The DFT evaluation was made by using the Gaussian 03 rev. A.01 suit program [6, 15] by applying DFT/B3LYP level with $6.31 \mathrm{G}(\mathrm{d}, \mathrm{p})$ basic set. The bond parameters (bond angles and bond lengths) of the optimized ligand were calculated. The single point energy $\left(-10.6583 \times 10^{5}\right.$ a.u.) and dipole moment (1.676 Debye) of the SB ligand were examined. The HOMO and LUMO energies for the SB ligand were analyzed (Figure 6). Further, the negative values of $\mathrm{E}_{\text {Hомо }}$ $(-0.20432 \mathrm{eV})$ and $\mathrm{E}_{\text {LUMO }}(-0.06671 \mathrm{eV})$ confirmed stability of the ligand $[6,15,32]$. However, the difference in energy $\left(\mathrm{E}_{\mathrm{HOMO}}-\mathrm{E}_{\mathrm{LUMO}}\right)$ for the ligand $(\Delta \mathrm{E}=0.13761 \mathrm{eV})$ was smaller suggesting the ligand is more reactive.

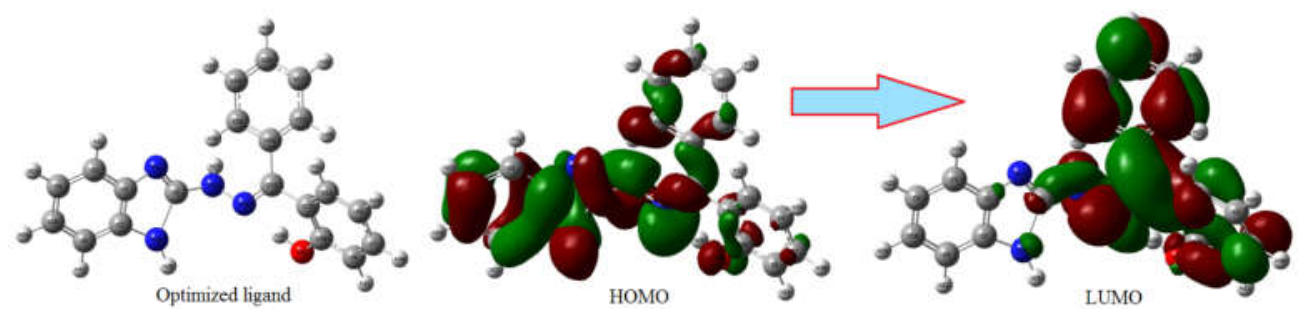

Figure 6. Optimized structure of the SB ligand with HOMO and LUMO represantations.

\section{QSAR study}

The QSAR technique is very much useful to anticipate the activity, reactivity and properties of the reported compounds. All the calculations were accomplished by employing HyperChem Professional 8.0.3 program. The structure was optimized by $\left(\mathrm{MM}^{+}\right)$force field with semiempirical PM3 methods and the energy minimization method was accomplished with FletcherReeves conjugate gradient algorithm. The evaluated $\log \mathrm{P}$ value for the synthesized ligand is found to be 4.41. The significant role of $\log \mathrm{P}$ value is to explain the biological activity of the synthesized ligand. More specifically the important role of the $\log \mathrm{P}$ is to measure the permeability of the studied compound into the cell membrane $[33,34]$. Some other significant parameters such as mass, volume, surface area, refractivity, hydration energy, polarizability, free energy, total energy, and RMS gradient are also worked out to suggest the action of the compounds which is listed in Table 3. 
Table 3. QSAR rating for optimized ligand (HL1).

\begin{tabular}{|l|c|}
\hline Function & Ligand \\
\hline Surface area (approx) $\left(\AA^{2}\right)$ & 438.8 \\
\hline Surface area (grid) $\left(\AA^{2}\right)$ & 599.0 \\
\hline Volume $\left(\AA^{3}\right)$ & 994.1 \\
\hline Hydration energy $(\mathrm{kcal} / \mathrm{mol})$ & -15.58 \\
\hline Log P & 4.41 \\
\hline Refractivity $\left(\AA^{3}\right)$ & 20.50 \\
\hline Polarizability $\left(\AA^{3}\right)$ & 37.86 \\
\hline Mass $($ amu $)$ & 328.4 \\
\hline Total energy $(\mathrm{kcal} / \mathrm{mol})$ & 25.32 \\
\hline Dipole Moment $(\mathrm{Debye})$ & 1.004 \\
\hline Free energy $(\mathrm{kcal} / \mathrm{mol})$ & 25.32 \\
\hline RMS gradient $(\mathrm{kcal} / \AA$ mol$)$ & 0.0915 \\
\hline
\end{tabular}

Electrostatic potential surface analysis

The electrostatic potential (ESP) surface of the SB ligand (HL1) was discussed by using ArgusLab 4.0.1 software (Figure 7). The SB ligand was optimized by employing molecular mechanics force field $(\mathrm{MM}+)$ followed by semiempirical PM3 methods. The ESP surface of the ligand contains number of possible sites for the electrophilic attack and showed a specific data about the charge distribution. The negative regions were observed over azomethine nitrogen $(C=N)$, phenolic oxygen $(-\mathrm{OH})$, and benzimidazole ring nitrogen $(\mathrm{NH})$ atoms as shown by red color. However, other nitrogen atoms were not participated in coordination which may be due to steric effect.

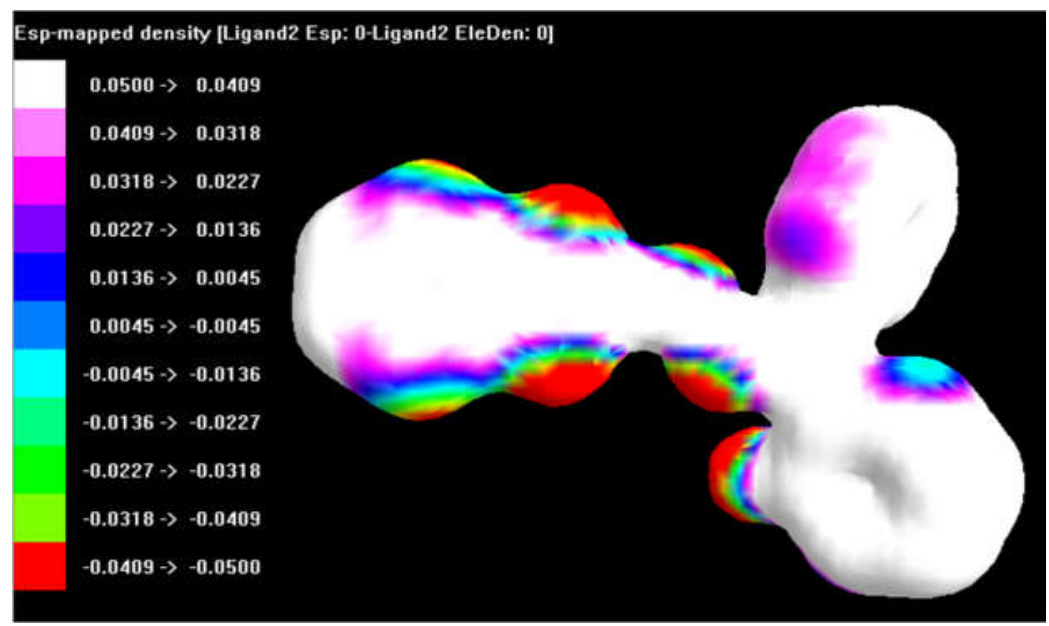

Figure 7. ESP structure of the SB ligand.

\section{CONCLUSION}

A series of ternary $\mathrm{Cu}(\mathrm{II}), \mathrm{Ni}(\mathrm{II}), \mathrm{Co}(\mathrm{II})$, and $\mathrm{Zn}$ (II) complexes were synthesized and investigated. The observations suggested that all these metal complexes are neutral in nature and contain lattice water molecules. As per the spectral study, the reported ternary compounds have octahedral geometry in which the SB ligand coordinates through tridentate manner with the metal ion. 
Moreover, these metal complexes exhibited weak to moderate antibacterial activity. However, the $\mathrm{Co}$ (II) complex displayed greater activity $(\mathrm{ZI}=17.32 \mathrm{~mm})$ as compared to all other metal complexes. Moreover, molecular docking study was carried out against MERS-CoV and SARS$\mathrm{CoV}-2$ main protease. It was observed that all these metal complexes have two violations of the parameters involved in Lipinski's rule.

\section{ACKNOWLEDGEMENT}

The authors are thankful to the authorities of Centurion University of Technology and Management (CUTM), Odisha, India for providing necessary facilities.

\section{REFERENCES}

1. Amani, V.; Safari, N.; Khavasi, H.R.; Mirzaei, P. Iron(III) mixed-ligand complexes: Synthesis, characterization and crystal structure determination of iron(III) hetero-ligand complexes containing 1,10-phenanthroline, 2,2'-bipyridine, chloride and dimethyl sulfoxide, [Fe(phen) $\mathrm{Cl}_{3}$ (DMSO)] and [Fe(bipy) $\mathrm{Cl}_{3}$ (DMSO)]. Polyhedron 2007, 26, 4908-4914.

2. El-ajaily, M.M.; Maihub, A.A.; Mahanta, U.K.; Badhei, G.; Mohapatra, R.K.; Das, P.K. Mixed ligand complexes containing Schiff bases and their biological activities: A short review. Rasayan J. Chem. 2018, 11, 166-174.

3. Lima, S.; Banerjee, A.; Mohanty, M.; Sahu, G.; Kausar, C.; Patra, S.K.; Garribba, E.; Kaminsky, W.; Dinda, R. Synthesis, structure and biological evaluation of mixed ligand oxidovanadium(IV) complexes incorporating 2-(arylazo)phenolates. New J. Chem. 2019, 43, 17711-17725.

4. Vairalakshmi, M.; Princess, R.; Rani, B.K.; Raja, S.J. Synthesis, structural elucidation, catalytic, antibacterial and antioxidant activity of thiophene derived mixed ligand metal complexes. J. Chil. Chem. Soc. 2018, 63, 3844-3849.

5. Mirjana, A.-N.; Branka, D.; Jelena, A.-S.; Sladana, T. New mixed-ligand Ni(II) and Zn(II) macrocyclic complexes with bridged (endo,endo)-bicyclo[2.2.1]hept-5-ene-2,3dicarboxylate: Synthesis, characterization, antimicrobial and cytotoxic activity. J. Serb. Chem. Soc. 2019, 84, 961-973.

6. El-Barasi, N.M.; Miloud, M.M.; El-ajaily, M.M.; Mohapatra, R.K.; Sarangi, A.K.; Das, D.; Mahal, A.; Parhi, P.K.; Pintilie, L.; Barik, S.R.; Bitu, N.A.; Zahan, K.-E.; Tabassum, Z.; AlResayes, S.I.; Azam, M. Synthesis, structural investigations and antimicrobial studies of hydrazone based ternary complexes with $\mathrm{Cr}(\mathrm{III}), \mathrm{Fe}(\mathrm{III})$ and La(III) ions. J. Saudi Chem. Soc. 2020, 24, 492-503.

7. Qamar, N.; Sultan, H.; Khan, K.M.; Azmat, R.; Naz, R.; Hameed, A.; Lateef, M. 8Hydroxyquinoline-methionine mixed ligands metal complexes: Preparation and their antioxidant activity. ChemistrySelect 2019, 4, 3058-3061.

8. Pravin, N.; Raman, N. DNA interaction and antimicrobial activity of novel tetradentate iminooxalato mixed ligand metal complexes. Inorg. Chem. Commun. 2013, 36, 45-50.

9. Mohamed, A.A.; Sadeek, S.A.; El-Hamid, S.M.A.; Zordok, W.A.; Awad, H.M. Mixed-ligand complexes of tenoxicam drug with some transition metal ions in presence of 2,2'-bipyridine: Synthesis, spectroscopic characterization, thermal analysis, density functional theory and in vitro cytotoxic activity. J. Mol. Struc. 2019, 1197, 628-644.

10. Omar, M.M.; El-Halim, H.F.A.; Khalil, E.A.M. Synthesis, characterization, and biological and anticancer studies of mixed ligand complexes with Schiff base and 2,2'-bipyridine. Appl. Organometal. Chem. 2017, 31, e3724.

11. Chipem, F.A.S.; Behera, S.K.; Krishnamoorthy, G. Excited state proton transfer of 2-(2'hydroxyphenyl)benzimidazole and its nitrogen substituted analogues in bovine serum albumin. Photochem. Photobiol. Sci. 2014, 13, 1297-1304. 
12. Mohapatra, R.K.; Das, P.K.; Kandi, V. Challenges in controlling COVID-19 in migrants in Odisha, India. Diabetes Metab. Syndr. Clin. Res. Rev. 2020, 14, 1593-1594.

13. Mohapatra, R.K.; Sarangi, A.K.; Kandi, V.; Azam, M.; Tiwari, R.; Dhama, K. Omicron (B.1.1.529 variant of SARS-CoV-2); an emerging threat: current global scenario. J. Med. Virol. 2021, doi: 10.1002/jmv.27561.

14. Mohapatra, R.K.; Tiwari, R.; Sarangi, A.K.; Sharma, S.K.; Khandia, R.; Saikumar, G.; Dhama, K. Twin combination of Omicron and Delta variant triggering a Tsunami wave of ever high surges in COVID-19 cases: A challenging global threat with a special focus on Indian sub-continent. J. Med. Virol. 2022, doi: 10.1002/jmv. 27585.

15. Mohapatra, R.K.; Perekhoda, L.; Azam, M.; Suleiman, M.; Sarangi, A.K.; Semenets, A.; Pintilie, L.; Al-Resayes, S.I. Computational investigations of three main drugs and their comparison with synthesized compounds as potent inhibitors of SARS-CoV-2 main protease (Mpro): DFT, QSAR, molecular docking, and in silico toxicity analysis. J. King Saud. Univ. Sci. 2021, 33, 101315.

16. Abdalla, M.; Mohapatra, R.K.; Sarangi, A.K.; Mohapatra, P.K.; Eltayb, W.A.; Alam, M.; ElArabey, A.A.; Azam, M.; Al-Resayes, S.I.; Seidel, V.; Dhama, K. In silico studies on phytochemicals to combat the emerging COVID-19 infection. J. Saudi Chem. Soc. 2021, 25, 101367.

17. Vogel, A.I. A Hand Book of Quantitative Inorganic Analysis, 2nd ed., Longman, ELBS: London; 1969.

18. Mohapatra, R.K.; Das, P.K.; El-ajaily, M.M.; Mishra, U.K.; Dash, D.C. Synthesis, spectral, thermal, kinetic and antibacterial studies of transition metal complexes with benzimidazolyl2-hydrazones of $o$-hydroxyacetophenone, $o$-hydroxybenzophenone and $o$-vanillin. Bull. Chem. Soc. Ethiop. 2018, 32, 437-450.

19. Hemalatha, S.; Dharmaraja, J.; Shobana, S.; Subbaraj, P.; Esakkidurai, T.; Raman, N. Chemical and pharmacological aspects of novel hetero MLB complexes derived from NO2 type Schiff base and N2 type 1,10-phenanthroline ligands. J. Saudi Chem. Soc. 2020, 24, 6180.

20. Lever, A.B.P. Inorganic Electronic Spectroscopy, Elsevier: New York; 1968.

21. Nikolaev, A.V.; Lagvienko, V.A.; Myachina, I. Thermal Analysis, Academic Press: New York; 1969.

22. Mohapatra, R.K.; Dash, D.C. Synthesis and characterization of $\mathrm{UO}_{2}(\mathrm{VI}), \mathrm{Th}(\mathrm{IV}), \mathrm{ZrO}(\mathrm{IV})$ and VO(IV) complexes with Schiff-base octaazamacrocyclic ligands. J. Korean Chem. Soc. 2010, 54, 395-401.

23. Mohapatra, R.K. Synthesis and characterization of $\mathrm{UO}_{2}(\mathrm{VI})$, Th(IV) and VO(IV) complexes with a Schiff base and their derivatives with chloroacetic acid. J. Indian Chem. Soc. 2010, 87, $1251-1255$.

24. Rahman, A.; Choudry, M.I.; Thomsen, W.J. Bioassay Techniques for Drug Development, Harwood Academic Publishers: Netherlands; 2001.

25. El-Ella, D.A.; Gonitzer, E.; Wendelin, W. Synthesis and structural elucidation of pyrimido[1,2-a]benzimidazoles and fused derivatives. I. Dihydropyrimido[1,2-a]benz. imidazoles. $J$. Heterocycl. Chem. 1996, 33, 373-382.

26. Balhausen, C.J. An Introduction to Ligand Field, McGraw Hill: New York; 1962.

27. CLC Drug Discovery Workbench, available at: http://www.clcbio.com.

28. Yu, X.; Zhang, S.; Jiang, L.; Cui, Y.; Li, D.; Wang, D.; Wang, N.; Fu, L.; Shi, X.; Li, Z.; Zhang, L.; Wang, X. Structural basis for the neutralization of MERS-CoV by a human monoclonal antibody MERS-27. Sci. Rep. 2015, 5, 13133.

29. Mesecar, A.D. A taxonomically-driven approach to development of potent, broad-spectrum inhibitors of coronavirus main protease including SARS-CoV-2 (COVID-19). 2020, 10.2210/pdb6W63/pdb. Available at: https://www.wwpdb.org/pdb?id=pdb_00006w63. 
30. Korb, O.; Stützle, T.; Exner, T.E. Empirical scoring functions for advanced protein-ligand docking with plants. J. Chem. Inf. Model. 2009, 49, 84-96.

31. Lipinski, C.A.; Lombardo, F.; Dominy, B.W.; Feeney, P.J. Experimental and computational approaches to estimate solubility and permeability in drug discovery and development settings. Adv. Drug Del. Rev. 2001, 46, 3-26.

32. Yousef, T.A.; Rakha, T.H.; El-Ayaan, U.; El-Reash, G.M.A. Synthesis, spectroscopic characterization and thermal behavior of metal complexes formed with (Z)-2-oxo-2-(2-(2oxoindolin-3-ylidene)hydrazinyl)-N-phenylacetamide ( $\left.\mathrm{H}_{2} \mathrm{OI}\right)$. J. Mol. Struct. 2012, 1007, 146-157.

33. Sarangi, A.K.; Mahapatra, B.B.; Sethy, S.K. Synthesis and characterization of tetranuclear metal complexes with an octadentate azodye ligand. Chem. Afr. 2018, 1, 17-28.

34. Padmanabhan, J.; Parthasarathi, R.; Subramanian, V.; Chattaraj, P. Molecular structure, reactivity, and toxicity of the complete series of chlorinated benzenes. J. Phys. Chem. 2005, 109, 11043-11049. 